\title{
STRATEGI PENGEMBANGAN PENGELOLAAN PASAR OLEH PERUSAHAAN DAERAH PASAR PAKUAN JAYA: PENDEKATAN BISNIS MODEL KANVAS
}

\author{
MARKET DEVELOPMENT STRATEGY ON PERUSAHAAN DAERAH PASAR PAKUAN JAYA : \\ CANVAS MODEL BUSINESS APPROACH
}

\author{
Khairunnisa*)1, Arief Daryanto*), dan Kirbrandoko **) \\ *) Sekolah Bisnis, IPB University \\ Jl. Raya Pajajaran Bogor 16151 \\ ${ }^{* *}$ Pascasarjana Universitas Ibn Khaldun \\ Jl. K.H. Sholeh Iskandar Km. 2 Bogor 16162
}

\begin{abstract}
Perusahaan Daerah Pasar Pakuan Jaya (PDPPJ) is the company that manages the traditional market in the city of Bogor. The presence of the modern retail industry, the existence of society's stigma, and various problems have stalled the development of traditional markets. PDPPJ needs the right business model to achieve its vision and mission and develop its future business. An approach that suitable to evaluate PDPPJ's problem is the business model canvas. The approach will be able to evaluate the existing PDPPJ business model. The objective of the study is to identify and map the current PDPPJ canvas business model, evaluate elements of business models with strength, weakness, opportunity, and threat (SWOT) analysis, and design the development of canvas business models. In addition, the research was conducted based on the traders' and buyers' perspectives concerning the services provided by PDPPJ. Another evaluation method was benchmarking analysis. The results of the two analyses were used as supporting data to develop the strategy based on the canvas business model at PDPPJ. The results of the study show that PDPPJ needed to give special attention to each element of its business model. PDPPJ might take advantage of existing opportunities to improve the quality of its services according to customer needs.
\end{abstract}

Keywords: benchmarking, BMC, customer perception, SWOT, traditional market

\begin{abstract}
Abstrak: Perusahaan Daerah Pasar Pakuan Jaya (PDPPJ) merupakan pengelola pasar tradisional di Kota Bogor. Hadirnya industri ritel modern, stigma masyarakat, serta berbagai permasalahan menyebabkan sulitnya pasar tradisional untuk berkembang. Agar dapat berkembang, PDPPJ membutuhkan model bisnis yang tepat guna mencapai visi dan misi perusahaan. Salah satunya dengan menggunakan pendekatan business model canvas (BMC) untuk mengetahui mengevaluasi model bisnis yang dijalankan oleh perusahaan agar dapat berjalan secara berkelanjutan. Penelitian ini bertujuan mengidentifikasi dan memetakan model bisnis kanvas PDPPJ saat ini, mengevaluasi elemen model bisnis dengan analisis strength, weakness, opportunity, dan threat (SWOT), serta membuat desain pengembangan model bisnis kanvas. Selain itu, dilakukan penelitian pandangan pedagang dan pembeli terhadap layanan yang diberikan oleh PDPPJ, serta analisis benchmarking. Hasil kedua analisis tersebut digunakan sebagai data pendukung dalam membuat desain strategi pengembangan model bisnis kanvas di PDPPJ. Hasil penelitian menunjukkan bahwa PDPPJ perlu memberikan perhatian khusus pada tiap-tiap elemen model bisnisnya, terutama pada elemen key activities dan key resources. PDPPJ dapat memanfaatkan peluang yang ada untuk meningkatkan kualitas layanannya sesuai dengan kebutuhan pelanggan.
\end{abstract}

Kata kunci: benchmark, model bisnis kanvas, pasar tradisional, persepsi pelanggan, model bisnis kanvas

\footnotetext{
${ }^{1}$ Corresponding author:

Email: khairunnisarunnis@gmail.com
} 


\section{PENDAHULUAN}

Pelimpahan kewenangan pusat kepada daerah memberikan pengaruh signifikan bagi sistem tata pemerintahan daerah. Sesuai dengan Undang-Undang No 23 tahun 2014, pemerintah daerah dapat menjadikan pajak dan retribusi yang ada di daerah tersebut sebagai sumber Pendapatan Asli Daerah (PAD). Salah satu potensi yang dimiliki oleh Kota Bogor adalah sektor Perdagangan Besar dan Eceran. Sektor tersebut menjadi kontributor terbesar bagi PDRB Kota Bogor. Pada periode 2011-2015, subsektor Perdagangan Besar dan Eceran menyumbang rata-rata 19,28\% dari PDRB Kota Bogor (BPS, 2018). Salah satu penyokong sektor Perdagangan adalah bisnis ritel pasar tradisional.

Akan tetapi, supermarketisasi atau perkembangan struktur ritel modern yang pesat terjadi di negaranegara berkembang (Reardon et al. 2005). Kehadiran industri ritel modern tersebut yang memanfaatkan pola belanja masyarakat kelas menengah ke atas membuat popularitas pasar tradisional menurun (Soliha, 2008). Stigma buruk juga dimiliki oleh pasar tradisional, yaitu kotor, bau, kumuh, serta semrawut. Terdapat beberapa faktor yang menyebabkan pertumbuhan ritel modern mengalami peningkatan yang pesat, yaitu kontinuitas transformasi dan inovasi yang konsisten (Reardon et al. 2010). Ritel modern juga unggul dari sisi pelayanan, kelengkapan varietas produk, dan kepastian harga (Muslimin et al. 2011). Produk berkualitas tinggi, harga yang bersaing, serta kondisi infrastruktur pasar ritel modern yang nyaman menjadi kekuatan yang tidak dimiliki oleh pasar tradisional saat ini (Suryadarma et al. 2007). Persaingan yang tidak seimbang tersebut menempatkan pasar tradisional dalam posisi yang lemah.

Kebijakan yang dilakukan oleh Pemerintah Daerah Kota Bogor untuk meningkatkan sumbangsih pasar tradisional adalah melalui peningkatan pengelolaan pasar tradisional sebagai basis kekuatan ekonomi rakyat. Saat ini terdapat 12 pasar tradisional di Kota Bogor dikelola oleh PD Pasar Pakuan Jaya (PDPPJ), yang terbagi menjadi tiga kelas, pasar regional yang terdiri atas Pasar Baru Bogor, Plaza Bogor, dan Pasar Kebon Kembang; pasar kota terdiri dari Pasar Devris, Pasar Taman Kencana, Pasar Merdeka, Pasar Sukasari, Pasar Padasuka, Pasar Pamoyanan, dan Pasar Gunung Batu; pasar wilayan yang terdiri dari Pasar Jambu Dua dan Pasar Tanah Baru.
Pengelolaan pasar tradisional oleh PDPPJ menghadapi berbagai permasalahan. Namun, yang menjadi masalah utama adalah rendahnya okupansi kios dan los yang menjadikan potensi pasar tradisional di Kota Bogor sebagai pusat perekonomian rakyat tidak termanfaatkan dengan maksimal. Sebanyak 40,8\% kios dan 34\% los yang tersebar di pasar-pasar tradisional Kota Bogor masih belum terisi (Disperindag, 2016a).

PD Pasar Pakuan Jaya (PDPPJ) diharapkan dapat berperan dalam mendorong pertumbuhan perekonomian daerah dan menjadi sebagai salah satu sumber pendapatan asli daerah (PAD). Berdasarkan sumbangsih perusahaan daerah terhadap PAD (20142016), proporsi dari PDPPJ sebesar 7\% masih sangat rendah dibandingkan badan usaha daerah lainnya, yakni PDAM yang mencapai 68\% (Disperindag, 2016b). PDPPJ sebagai pengelola utama pasar tradisional di Kota Bogor perlu melakukan kajian yang lebih mendalam sebagai pertimbangan dalam strategi pengembangan pengelolaan pasar, khususnya sebagai upaya peningkatan pendapatan perusahaan yang akan berpengaruh bagi pendapatan asli daerah. PDPPJ, sebagai perusahaan yang tumbuh dan berkembang membutuhkan model bisnis yang tepat guna mencapai visi dan misi perusahaan (Nurhakim et al. 2018). Salah satunya dengan menggunakan pendekatan business model canvas untuk mengetahui mengevaluasi model bisnis yang dijalankan oleh perusahaan agar dapat berjalan secara berkelanjutan. Business Model Canvas (BMC) merupakan pengembangan dari penelitian Osterwalder (2004) yang berjudul The Business Model Ontology a Proposition in a Design Science Approach yang diharapkan akan membantu memahami, menjelaskan dan memprediksi aktivitas yang sebaiknya dilakukan untuk menghasilkan keuntungan bagi perusahaan. BMC digunakan untuk memahami kondisi suatu organisasi dan melakukan inovasi terhadap model bisnis pada organisasi tersebut (Qastharin, 2016).

Terdapat beberapa kajian yang menjadi acuan dalam penelitian ini. Penelitian pertama yang dilakukan oleh Bakri (2011) menyimpulkan bahwa peningkatan kualitas pelayanan, peningkatan sarana prasarana dan pengaturan PKL pasar perlu dilakukan untuk meningkatkan posisi tawar. Sari (2012) melakukan penelitian mengenai model pengelolaan pasar yang ada di Kota Dumai yang menerangkan bahwa model pengelolaan pasar yang potensial untuk diterapkan adalah model pengelolaan terpusat, dan perlunya kerjasama antar berbagai pihak karena strategi tersebut 
baru dapat terlaksana bila kerjasama dilakukan dengan baik. Youssef et al. (2016) menunjukan bahwa model BMC harus dihubungkan dengan proses inovasi, terutama pada peningkatan human capital key.

Tujuan penelitian ini adalah (1) mengidentifikasi dan memetakan kondisi bisnis model perusahaan saat ini menggunakan pendekatan BMC, (2) mengidentifikasi kondisi pengelolaan pasar tradisional oleh PDPPJ berdasarkan persepsi pelanggan dan benchmarking dengan wilayah lain, kemudian (3) membuat strategi pengembangan pengelolaan pasar tradisional oleh PDPPJ melalui program perbaikan pada model bisnis kanvas yang disempurnakan.

\section{METODE PENELITIAN}

Penelitian dilaksanakan pada PDPPJ yang beralamat di J1 Siliwangi Blok Gardu Tinggi No 31, Sukasari, Kota Bogor. Penelitian juga dilaksanakan di pasar-pasar yang dikelola oleh PDPPJ yang tersebar di wilayah Kota Bogor. Penelitian dilaksanakan pada bulan November 2017-Desember 2018.

Penelitian menggunakan data primer yang diperoleh dari hasil observasi dan wawancara mendalam kepada direksi dan badan pengawas PDPPJ, 20 orang pedagang yang telah berjualan minimal selama tiga tahun di lokasi pasar PDPPJ, dan 20 orang pengunjung yang telah mengunjungi minimal tiga lokasi pasar
PDPPJ. Penentuan responden dilakukan dengan sengaja (purposive sampling), dan untuk responden analisis BMC dilakukan dengan pendekatan expertise judgment. Data sekunder diperoleh dengan mengakses informasi/berasal dari instansi terkait seperti BPS Kota Bogor, Bappeda Kota Bogor, Disperindag Kota Bogor, dan sumber lainnya yang relevan seperti dari jurnal, buku, dan working paper.

Tahap pengolahan dan analisis data melalui tahapan berikut: (1) Analisis deskriptif untuk mendapatkan gambaran umum mengenai kondisi perusahaan, visi, misi, dan tujuan perusahaan yang dilakukan melalui wawancara mendalam terhadap tiga direktur PDPPJ, dan tiga orang badan pengawas PDPPJ, (2) Analisis SWOT terhadap sembilan elemen bisnis kanvas. Analisis SWOT digunakan untuk menidentifikasi berbagai faktor sistematis untuk merumuskan strategi perusahaan (Agustiadi et al. 2018), (3) Analisis persepsi pelanggan dilakukan terhadap pedagang dan pembeli melalui wawancara mendalam berdasarkan lima elemen service quality sebagai bahan evaluasi dari analisis SWOT, (4) Analisis benchmarking untuk mengetahui bagaimana posisi objek penelitian dibandingkan dengan pengelolaan di dua lokasi pasar lain, yakni Pasar Modern BSD di Serpong dan Pasar Rejowinangun di Magelang, (5) Perumusan strategi perbaikan model bisnis kanvas bagi pengelolaan pasar oleh PDPPJ. Secara keseluruhan sistematika penelitian dituangkan pada kerangka pemikiran penelitian yang digambarkan pada Gambar 1.

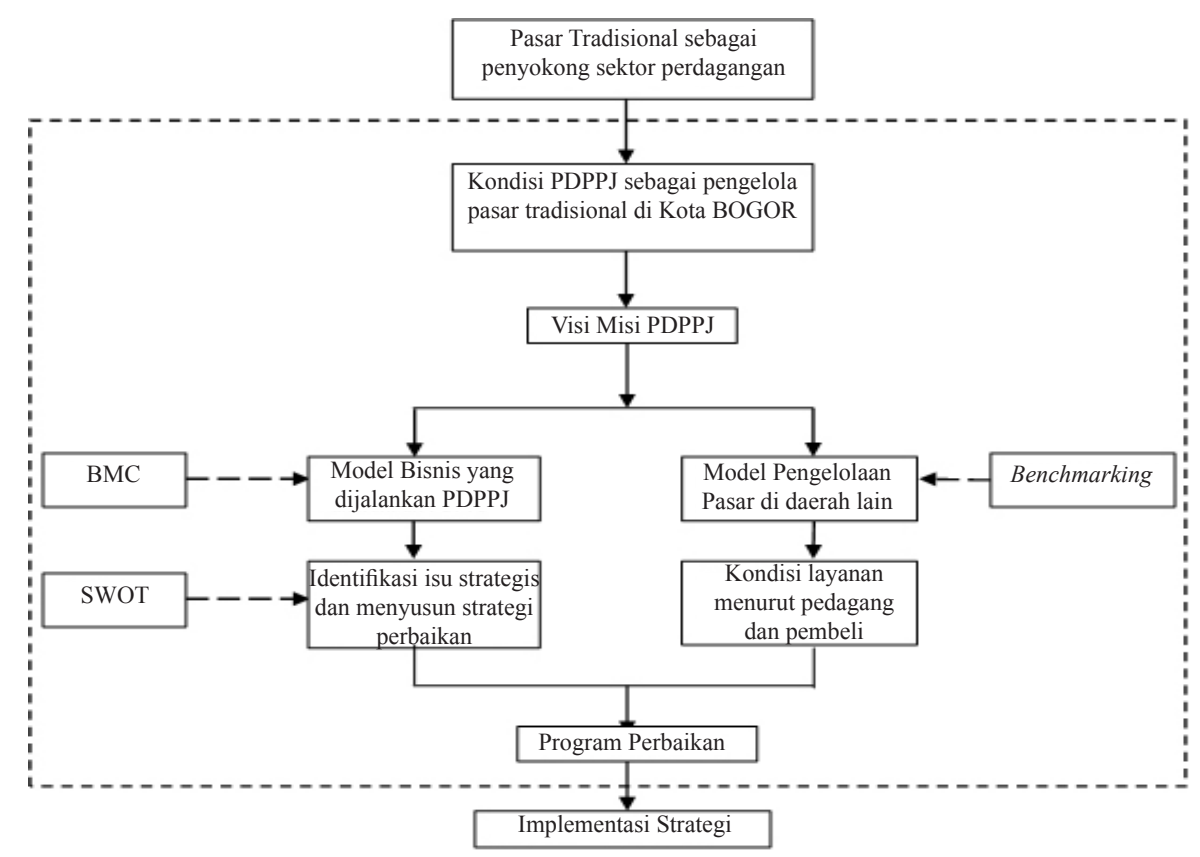

Gambar 1. Kerangka pemikiran penelitian 


\section{HASIL}

\section{Identifikasi Model Bisnis Kanvas PDPPJ}

Penelitian ini melibatkan orang-orang yang terkait dengan manajemen PDPPJ. Berdasarkan hasil penelitian sembilan elemen BMC dari Osterwalder dan Pigneur (2012), berikut gambaran kanvas model bisnis yang dijalankan oleh PDPPJ saat ini (Gambar 2).

Customer Segments menggambarkan orang atau organisasi berbeda yang ingin dijangkau atau dilayani oleh perusahaan. PD Pasar Pakuan Jaya sebagai perusaahan yang mengelola pasar tradisional melayani pedagang yang akan berjualan di kawasan pasar. Lingkup segmen konsumen yang sangat luas, mulai dari masyarakat dengan ekonomi rendah, menengah, hingga atas. Beberapa nilai yang ditawarkan oleh perusahaaan juga dinikmati oleh pengunjung yang datang ke pasar (pembeli).

Value Proposition merupakan nilai yang ditawarkan oleh perusahaan kepada pelanggan. Jasa layanan yang diberikan oleh PDPPJ adalah kemampuan dalam mengakses (accessibility) bagi pedagang untuk masuk dan menggunakan sarana pasar melalui layanan sewa kios dan los. Nilai lain yang ditawarkan bagi pedagang adalah membantu pedagang dalam pembuatan perizinan (getting the job done) BHPTB dan KIPTB yang wajib dimiliki oleh pedagang. Perusahaan juga menyediakan berbagai fasilitas penunjang untuk mendukung kenyamanan (convenience) wilayah pasar, seperti layanan perparkiran, fasilitas MCK, anjungan tunai mandiri (ATM), sarana penyewaan ruang dan reklame, pengelolaan kebersihan, ketertiban dan keamanan pasar, pengelolaan listrik, serta layanan bongkar muat bagi pedagang. Keberadaan pasar tradisional membantu para pengunjung dapat melakukan tawar menawar dengan pedagang untuk mendapatkan harga yang lebih murah (cost reduction).

Channels (saluran) yang digunakan oleh PD Pasar Pakuan Jaya berupa saluran langsung melalui kantor pusat dan kantor unit kepada pelanggan. Perusahaan memiliki website yang dapat diakses oleh seluruh masyarakat untuk mengetahui proposisi nilai yang ditawarkan oleh perusahaan, serta layanan call center bagi pengunjung untuk memperoleh informasi, memberikan saran, kritik, dan masukan bagi perusahaan.

Customer Relationship PDPPJ bersifat personal assistance (bantuan personal) dengan para pedagang melalui kantor pusat dan kantor unit. Pedagang langsung bertemu dengan perusahaan untuk membuat perizinan, melakukan penyewaan, dan penyampaian permasalahan ataupun saran bagi perusahaan. Perusahaan juga memiliki info bagi pelanggan dan calon pelanggan mengenai kegiatan, jasa yang ditawarkan hingga pergerakan harga di pasar. Selain itu, perusahaan memiliki call center yang dapat digunakan oleh masyarakat sebagai media untuk berkomunikasi dengan perusahaan.

\begin{tabular}{|c|c|c|c|c|}
\hline Key Partner & Key Activities & Value Proposition & Customer Relationship & Customer Segment \\
\hline \multirow{3}{*}{$\begin{array}{l}\text { - Investor } \\
\text { - Pihak Ketiga } \\
\text { (Pengelola parkir, } \\
\text { bongkar muat, } \\
\text { kebersihan, MCK) }\end{array}$} & $\begin{array}{l}\text { - Pembangunan dan } \\
\text { Pemeliharaan } \\
\text { - Pengelolaan dan } \\
\text { Pengawasan }\end{array}$ & \multirow[t]{3}{*}{$\begin{array}{l}\text { - Accessibility } \\
\text { - Getting the job done } \\
\text { - Cost reduction } \\
\text { - Convenience/usability }\end{array}$} & $\begin{array}{l}\text { - Kantor pusat dan } \\
\text { kantor unit } \\
\text { - Website dan call } \\
\text { center }\end{array}$ & \multirow[t]{3}{*}{$\begin{array}{l}\text { - Pedagang } \\
\text { - Pembeli }\end{array}$} \\
\hline & Key Resources & & Channel & \\
\hline & $\begin{array}{l}\text { - Sumber daya fisik } \\
\text { (bangunan) } \\
\text { - Sumber daya manusia }\end{array}$ & & $\begin{array}{l}\text { - Saluran langsung } \\
\text { (kantor unit, website, } \\
\text { call center) }\end{array}$ & \\
\hline \multicolumn{2}{|l|}{ Cost Structure } & \multicolumn{2}{|c|}{ Revenue Streams } & \\
\hline \multicolumn{2}{|l|}{$\begin{array}{l}\text { - Biaya umum } \\
\text { - Perawatan infrastruktur } \\
\text { - Biaya tenaga kerja }\end{array}$} & \multicolumn{2}{|c|}{$\begin{array}{l}\text { - Biaya sewa } \\
\text { - Investor } \\
\text { - Profit sharing jasa layanan }\end{array}$} & \\
\hline
\end{tabular}

Gambar 2. Sembilan Elemen BMC PD Pasar Pakuan Jaya saat ini 
Revenue Stream dipengaruhi kesediaan pelanggan dalam membayarnilai yang ditawarkan oleh perusahaan. Pendapatan utama perusahaan berasal dari pembayaran sewa, baik kios dan los, penyewaan reklame, maupun penyewaan lokasi ruang terbuka. Pendapatan dari pembayaran sewa merupakan pendapatan berulang.

Key Resources terbagi menjadi dua, yakni sumber daya yang terlihat (tangible) dan tidak terlihat (intangible). Sumber daya tangible merupakan sumber daya fisik berupa gedung-gedung pasar yang tersebar di berbagai wilayah Kota Bogor. Sementara itu, sumber daya intangible adalah sumber daya manusia yang dimiliki perusahaan dan memiliki keahlian dalam pengelolaan pasar.

Key Activity yang dilakukan oleh PDPPJ adalah pengelolaan pasar dan pengawasan bahan berbahaya, serta pembangunan dan pemeliharaan infrastruktur pasar. Pembangunan dan pemeliharaan infrastruktur dilakukan secara bertahap disesuaikan dengan kebutuhan masing-masing pasar.

Key Partnership dari PDPPJ adalah kerjasama dengan sistem bagi hasil dengan pihak ketiga dalam memberikan pelayanan MCK, kebersihan, bongkar muat, dan parkir. Perusahaan juga bekerjasama dengan perusahaan (investor) dalam melakukan revitalisasi pasar. PD Pasar Pakuan Jaya sebagai perusahaan daerah juga bekerjasama dengan dinas-dinas terkait seperti Dinas UMKM, Dinas Perindustrian, Dinas Pertanian, Dinas Kebersihan, dan Dinas Kesehatan Kota Bogor.

Cost Structure, biaya yang dikeluarkan oleh PPDPPJ terbagi menjadi tiga, yakni biaya umum untuk pengeluaran perusahaan berupa kebutuhan pengadaan ATK, seragam, biaya rapat, dan pembayaran listrik. Pengeluaran lainnya yakni biaya tenaga kerja dan pemeliharaan infrastruktur pasar.

\section{Analisis SWOT terhadap sembilan elemen Business Model Canvas PDPPJ}

Analisis SWOT (Tabel 1) dilakukan terhadap empat perspektif penilaian SWOT (strength, weakness, opportunities, threats) pada sembilan elemen model bisnis yang bertujuan sebagai evaluasi model bisnis (Susanto, 2017). Hasil analisis SWOT digunakan untuk menyempurnaan model bisnis yang telah diterapkan dan membuat strategi pengembangan perusahaan agar dapat diketahui elemen mana yang dapat dioptimalkan, diperbaiki, ataupun dirubah untuk keberlangsungan organisasi di masa yang akan datang (Prabuwisudawan et al. 2018).

\section{Kualitas Layanan Berdasarkan Persepsi Pedagang dan Pembeli}

Pedagang dan pembeli merupakan aset penting yang harus diperhatikan oleh perusahaan sebagai penyedia jasa pengelolaan pasar. Citra suatu perusahaan tidak dilihat dari sudut pandang perusahaan, melainkan dari sudut pandang pelanggannya, dan perusahaan yang mampu memberikan kepuasan kepada pelanggannya adalah perusahaan yang mengerti akan harapan dari pelanggannya (Kotler dan Keller, 2009). Melalui lima elemendalamservicequality, yaknitangiable(berwujud), reliability (kehandalan), responsiveness (daya tanggap), assurance (jaminan/kepastian), empathy (kepedulian), diharapkan pelanggan (pedagang dan pembeli) akan merasa puas dan loyal atas layanan yang diberikan oleh perusahaan. Kualitas memberikan suatu dorongan kepada pelanggan untuk menjalin ikatan hubungan yang kuat dengan perusahaan (Prasetio et al. 2012). Pelanggan yang loyal dapat memberikan keuntungan yang lebih besar bagi perusahaan serta menumbuhkan pendapatan dengan cara menawarkan produk lainnya (cross selling) yang bertujuan meningkatkan frekuensi dan volume transaksi pelanggan (Wijaya et al. 2017).

Tabel 2 menunjukkan bahwa pedagang merasa layanan yang diberikan oleh PDPPJ sudah cukup baik, akan tetapi yang perlu menjadi perhatian khusus adalah mengenai kondisi bangunan dan layout pasar, lokasi kios dan los, serta permasalahan penataan pedagang kaki lima yang ada di sekitaran pasar. Ketiga hal tersebut sangat berpengaruh pada jumlah pengunjung yang datang ke lokasi pasar, yang berdampak pada tingkat penjualan pedagang. Menurut pengunjung (pembeli), kondisi bangunan pasar, layout, dan zonasi komoditas masih menjadi faktor yang perlu dibenahi oleh PDPPJ. Keberadaan fasilitas umum yang menunjang kenyamanan bagi pengunjung juga perlu ditingkatkan, seperti penataan sarana parkir yang lebih baik lagi. Pengunjung juga menyatakan bahwa kurang mengetahui akan adanya layanan call center yang menjadi pusat informasi dan aspirasi PDPPJ. 
Tabel 1. Penentuan SWOT dari sembilan elemen Business Model Canvas PDPPJ

\begin{tabular}{|c|c|c|c|c|}
\hline Elemen & Kekuatan (S) & Kelemahan (W) & Peluang (O) & Ancaman (T) \\
\hline $\begin{array}{l}\text { Customer } \\
\text { Segment }\end{array}$ & $\begin{array}{l}\text { PDPPJ mampu melayani } \\
\text { segmen pelanggan yang } \\
\text { berbeda }\end{array}$ & $\begin{array}{l}\text { Tingkat berpindahnya } \\
\text { pelanggan tinggi. }\end{array}$ & $\begin{array}{l}\text { Pengembangan produk } \\
\text { (layanan) baru untuk } \\
\text { segmen pelanggan lama } \\
\text { maupun baru. }\end{array}$ & $\begin{array}{l}\text { Beralihnya pelanggan } \\
\text { karena adanya pesaing }\end{array}$ \\
\hline $\begin{array}{l}\text { Value } \\
\text { Proposition }\end{array}$ & $\begin{array}{l}\text { Proporsi nilai yang } \\
\text { ditawarkan sesuai } \\
\text { dnegan kebutuhan } \\
\text { pelanggan }\end{array}$ & $\begin{array}{l}\text { Proporsi nilai terbatas } \\
\text { sesuai dengan aturan } \\
\text { yang berlaku }\end{array}$ & $\begin{array}{l}\text { Adanya kebutuhan } \\
\text { tambahan pelanggan } \\
\text { yang dapat dipenuhi }\end{array}$ & $\begin{array}{l}\text { Adanya pesaing yang } \\
\text { memiliki produk dan } \\
\text { jasa substitusi }\end{array}$ \\
\hline Channels & $\begin{array}{l}\text { PDPPJ memiliki saluran } \\
\text { yang efektif dan efisien }\end{array}$ & $\begin{array}{l}\text { Jangkauan saluran } \\
\text { lemah terhadap } \\
\text { pelanggan baru }\end{array}$ & $\begin{array}{l}\text { Pemanfaatan saluran } \\
\text { melalui mitra perusahaan }\end{array}$ & $\begin{array}{l}\text { Saluran pesaing yang } \\
\text { lebih baik dari PDPPJ }\end{array}$ \\
\hline $\begin{array}{l}\text { Customer } \\
\text { Relathionship }\end{array}$ & $\begin{array}{l}\text { Kualitas hubungan } \\
\text { PDPPJ sesuai dengan } \\
\text { segmen pelanggan }\end{array}$ & $\begin{array}{l}\text { Belum } \\
\text { termanfaatkannya } \\
\text { database pelanggan }\end{array}$ & $\begin{array}{l}\text { Pelayanan yang lebih } \\
\text { baik berdasarkan } \\
\text { pengaduan, masukan, } \\
\text { kritik, dan saran dari } \\
\text { pelanggan }\end{array}$ & $\begin{array}{l}\text { Komunikasi antara } \\
\text { pesaing dengan } \\
\text { pelanggan lebih baik. }\end{array}$ \\
\hline $\begin{array}{l}\text { Revenue } \\
\text { Stream }\end{array}$ & $\begin{array}{l}\text { PDPPJ memiliki } \\
\text { arus pendapatan } \\
\text { berulang dan mendapat } \\
\text { pembelian berulang }\end{array}$ & $\begin{array}{l}\text { Belum adanya aturan } \\
\text { tegas untuk pembayaran } \\
\text { sewa }\end{array}$ & $\begin{array}{l}\text { Penciptaan arus } \\
\text { pendapatan lain }\end{array}$ & $\begin{array}{l}\text { Tidak terpenuhinya } \\
\text { target karena adanya } \\
\text { pesaing }\end{array}$ \\
\hline Key Activities & $\begin{array}{l}\text { Kegiatan operasional } \\
\text { sesuai dengan aturan } \\
\text { yang telah ditetapkan }\end{array}$ & $\begin{array}{l}\text { Banyaknya pihak yang } \\
\text { berhubungan dengan } \\
\text { aktivitas kunci }\end{array}$ & $\begin{array}{l}\text { Peningkatan kualitas } \\
\text { aktivitas kunci dengen } \\
\text { penetapan standar }\end{array}$ & $\begin{array}{l}\text { Sumber daya utama } \\
\text { yang kurang optimal }\end{array}$ \\
\hline Key Resources & $\begin{array}{l}\text { Kebutuhan sumber daya } \\
\text { utama dapat diprediksi }\end{array}$ & $\begin{array}{l}\text { Sumber daya fisik yang } \\
\text { kurang sesuai dengan } \\
\text { keinginan pelanggan }\end{array}$ & $\begin{array}{l}\text { Penciptaan layanan baru } \\
\text { dengan mengoptimalkan } \\
\text { penggunaan sumber daya }\end{array}$ & $\begin{array}{l}\text { Pesaing memiliki } \\
\text { sumber daya yang lebih } \\
\text { baik }\end{array}$ \\
\hline $\begin{array}{l}\text { Key } \\
\text { Partnership }\end{array}$ & $\begin{array}{l}\text { Kerjasama dengan mitra } \\
\text { berjalan dengan baik }\end{array}$ & $\begin{array}{l}\text { Adanya sistem bagi } \\
\text { hasil }\end{array}$ & $\begin{array}{l}\text { Penciptaan nilai melalui } \\
\text { kerjasama dengan mitra. }\end{array}$ & $\begin{array}{l}\text { Pelanggan kurang puas } \\
\text { dengan kinerja mitra }\end{array}$ \\
\hline Cost Structure & $\begin{array}{l}\text { Biaya PDPPJ dapat } \\
\text { diprediksi. }\end{array}$ & $\begin{array}{l}\text { Biaya perawatan } \\
\text { sumber daya tinggi. }\end{array}$ & $\begin{array}{l}\text { Penghematan biaya } \\
\text { tetap melalui kerjasama } \\
\text { dengan mitra. }\end{array}$ & $\begin{array}{l}\text { Adanya ketidakpatuhan } \\
\text { pelanggan dalam } \\
\text { melakukan pembayaran. }\end{array}$ \\
\hline
\end{tabular}

Tabel 2. Persepsi pelanggan dan pembeli terhadap kualitas layanan PDPPJ

\begin{tabular}{|c|c|c|}
\hline Elemen & Persepsi Pedagang & Persepsi Pembeli \\
\hline $\begin{array}{l}\text { Tangiable } \\
\text { (Berwujud) }\end{array}$ & $\begin{array}{l}\text { Lokasi pasar mudah dijangkau } \\
\text { Kondisi bangunan kurang nyaman (kotor, } \\
\text { pengap, lokasi kios los kurang strategis, } \\
\text { fasilitas umum kurang) }\end{array}$ & $\begin{array}{l}\text { Lokasi pasar mudah dijangkau (beberapa titik } \\
\text { macet) } \\
\text { Kondisi bangunan kurang nyaman (kotor, pengap, } \\
\text { lokasi kios los kurang strategis, becek) } \\
\text { Lahan parkir mobil minim } \\
\text { Penataan produk belum sesuai }\end{array}$ \\
\hline $\begin{array}{l}\text { Realiability } \\
\text { (Kehandalan) }\end{array}$ & $\begin{array}{l}\text { Kemampuan petugas cukup baik } \\
\text { Biaya cukup sesuai } \\
\text { Penataan PKL perlu ditingkatkan } \\
\text { Lokasi kios los terlalu rapat } \\
\text { Tidak ingin pengaturan zonasi ulang }\end{array}$ & $\begin{array}{l}\text { Lokasi kios dan los terlalu rapat } \\
\text { Zonasi komoditas ditingkatkan } \\
\text { PKL memudahkan bagi pelanggan, tetapi ingin } \\
\text { lebih ditata }\end{array}$ \\
\hline $\begin{array}{l}\text { Assurance } \\
\text { (Jaminan/ } \\
\text { Kepastian) } \\
\text { Responsiveness } \\
\text { (Daya Tanggap) } \\
\text { Empathy } \\
\text { (Kepedulian) }\end{array}$ & $\begin{array}{l}\text { Puas. Adanya kantor unit sangat membantu } \\
\text { pedagang dalam mengurus perizinan, adanya } \\
\text { petugas yang berkeliling untuk memantau } \\
\text { dan mengambil pembayaran, komunikasi } \\
\text { mudah tersampaikan, adanya pertemuan rutin } \\
\text { antara perusahaan dan pedagang. }\end{array}$ & $\begin{array}{l}\text { Produk lengkap, harga lebih murah, kualitas sesuai } \\
\text { Keamanan ketertiban terjaga } \\
\text { Tidak ada komunikasi langsung dengan perusahaan } \\
\text { Kurang informasi mengenai layanan call center }\end{array}$ \\
\hline
\end{tabular}




\section{Analisis Benchmarking}

Hasil dari analisis persepsi pelanggan yang telah dilakukan, terdapat beberapa aspek yang perlu mendapatkan perhatian lebih dari perusahaan, seperti kondisi bangunan, kebersihan, perparkiran dan bongkar muat. Oleh karena itu, PDPPJ dapat melakukan perbandingan dengan cara pengelolaan yang dilakukan oleh pengelola pasar lainnya melalui analisis benchmarking. Benchmarking merupakan ukuran kualitas kinerja perusahaan yang dibuat dengan membandingkan dengan perusahaan lain yang "terbaik di kelasnya" (Fitzsimmons et al. 2014). Terdapat dua lokasi pasar yang dijadikan tolak ukur bagi PDPPJ dalam melakukan pengelolaan pasar, yaitu Pasar Modern BSD yang berada di Serpong dan Pasar Rejowinangun di Magelang. Pasar Rejowinangun merupakan salah satu pasar tradisional yang menerima Anugerah Pancawara. Sementara itu, Pasar Modern BSD menjadi pasar percontohan berdasarkan Kementrian Perdagangan bagi pasar-pasar rakyat berbasis modern.

Hasil benchmarking pada Tabel 3, masih banyak aspek yang perlu dibenahi oleh PDPPJ. Aspek pertama yang perlu dibenahi adalah masalah kondisi bangunan, arsitektur dan layout bangunan, serta penataan zonasi komoditinya. Kondisi bangunan yang baik, arsitektur dan layout yang disesuaikan dengan kebutuhan akan meningkatkan keinginan pedagang untuk berjualan di lokasi tersebut, serta memberikan kenyamanan bagi pengunjung dalam berbelanja. Penataan zonasi komoditas akan memudahkan pengunjung dalam mencari komoditi, serta memberikan kesempatan yang sama bagi tiap-tiap pedagang untuk mendapatkan pembeli. Fasilitas umum yang ditawarkan oleh PDPPJ juga perlu ditingkatkan kualitasnya. Lokasi parkir khusus yang tidak mengganggu badan jalan, lokasi bongkar muat, fasilitas MCK, tempat ibadah, serta lokasi khusus pedagang kaki lima yang tertata akan meningkatkan kenyamanan bagi pedagang dan pembeli. Kondisi kebersihan pasar di pasar-pasar PDPPJ masih belum tertata dan dikelola dengan baik. PDPPJ perlu meningkatkan jumlah tenaga kebersihan dan lokasi sarana kebersihan yang ada di pasar. Apabila kondisi aspek-aspek tersebut mengalami peningkatan, maka tidak mustahil bagi PPDPPJ dapat setara dengan Pasar Modern dan Pasar Rejowinangun.

Tabel 3. Hasil analisis benchmarking

\begin{tabular}{lll}
\hline \multicolumn{1}{c}{ Aspek } & \multicolumn{1}{c}{ PD Pasar Pakuan Jaya } & \multicolumn{1}{c}{ Pasar Modern BSD } \\
\hline $\begin{array}{l}\text { Kondisi Bangunan dan } \\
\text { Arsitektur }\end{array}$ & $\begin{array}{l}\text { Bangunan lama, lokasi kios los berdempetan, } \\
\text { Sirkulasi udara tidak baik }\end{array}$ & $\begin{array}{l}\text { Bangunan baru, kios teratur rapi, lorong } \\
\text { lebar, atap tinggi, kios los teratur rapi }\end{array}$ \\
& Kurang tertata & $\begin{array}{l}\text { Tertata rapi secara spesifik sesuai } \\
\text { komoditi }\end{array}$ \\
Akses Lokasi & Mudah diakses namun banyak kemacetan & Mudah diakses \\
Lahan Parkir & Parkir motor tidak tertata & \\
Parkir mobil kurang jumlahnya & Tertata rapi dengan sistem otomatis & \\
Fasilitas Bongkar Muat & Tidak semua pasar memiliki lokasi bongkar & Terdapat di lokasi khusus sesuai \\
& muat & kebutuhan pedagang \\
Pembiayaan Pembangunan dan & Perusahaan, dibantu penyetaraan modal & Pihak manajemen perusahaan (Sinar \\
Perbaikan Pasar & pemerintah kota, dan bantuan investor & Mas Land) \\
Aspek & PD Pasar Pakuan Jaya & Pasar Rejowinangun \\
Fasilitas Umum & Ada, tidak lengkap dan kurang terawat & Lengkap dan terawat \\
Penampungan dan Pengelolaan & Tersedia, namun belum dikelola dengan baik & Tersedia di banyak titik dan sudah \\
Sampah & & dikelola dengan baik \\
Kebersihan Pasar & Kurang & Baik \\
Ketertiban Pedagang Pembeli & Kurang & Baik \\
\hline
\end{tabular}




\section{Rumusan Strategi Perbaikan}

Hasil analisis sembilan elemen bisnis model kanvas, perusahaan dapat memetakan kondisi riil perusahaan saat ini, melalui analisis persepsi pelanggan, perusahaan mengetahui permasalahan apa saja yang ada berdasarkan perspektif pelanggannya, dan mendapatkan gambaran mengenai kondisi yang lebih optimal untuk melakukan pengelolaan berdasarkan analisis benchmarking. Berdasarkan ketiga analisis tersebut, perusahaan dapat mengetahui permasalahan yang ada dan merumuskan strategi perbaikan. Perbaikan atau pengembangan akan mendorong perusahaan untuk beradaptasi dengan persaingan usaha yang semakin kompetitif. Pengembangan model bisnis kanvas PDPPJ selengkapnya pada Gambar 3. Berikut gambaran model bisnis.

\section{Key Activities}

Pembangunan dan pemeliharaan infrastruktur akan lebih maksimal apabila perusahaan fokus dalam perbaikan infrastruktur dengan standar yang lebih modern dan menyesuaikan kebutuhan para pelanggan. Perusahaan dapat melakukan program revitalisasi secara total, dengan melaksanakan kegiatan runtuh bangun salah satu pasar yang paling potensial untuk dikembangkan. Kegiatan ini akan memberikan kesempatan bagi perusahaan untuk menyesuaikan kondisi infrastruktur bangunan pasar sesuai dengan kondisi perbelanjaan yang lebih modern dan nyaman. Kegiatan ini juga akan memberikan pilihan bagi perusahaan untuk mempersiapkan layanan-layanan baru yang dapat diberikan kepada pelanggannya. Melalui kegiatan tersebut, aktivitas pengelolaan dan pengawasan juga dapat ditingkatkan melalui kerja sama secara lebih spesifik dengan mitra perusahaan. Perusahaan juga dapat meningkatkan kualitas layanan pengelolaan dengan menggunakan teknologi seperti penerapan e-retribusi dengan tujuan memantau pembayaran yang dilakukan pedagang, dan meningkatkan kepercayaan dari pelanggan karena tidak adanya kemungkinan terjadinya pungutan liar.

\section{Key Resources}

Penciptaan proposisi nilai yang sejalan dengan kebutuhan pelanggan dan nilai perusahaan perlu dilakukan dengan peningkatan promosi dan fasilitas (Wiska et al. 2016). Kondisi sumber daya fisik pasar saat ini tidak sesuai dengan visi misi perusahaan.
Melalui kegiatan revitalisasi pasar secara keseluruhan, permasalahan sumber daya fisik dapat tertangani. Program revitalisasi secara total ini juga perlu didukung dengan ditingkatkannya kapabilitas sumber daya manusia yang ada. Perusahaan membutuhkan pegawai yang lebih berpengalaman dalam hal pemasaran. Kegiatan pemasaran yang lebih aktif, baik secara langsung kepada calon pelanggan, maupun pemasaran melalui media sosial yang interaktif tentunya akan meningkatkan jumlah pelanggan.

\section{Value Proposition}

Adanya kegiatan revitalisasi secara total dapat meningkatkan kualitas value yang ditawarkan oleh perusahaan. Layanan-layanan yang selama ini masih kurang optimal, seperti kondisi parkir, bongkar muat, MCK, kebersihan, dan layanan fasilitas umum lainnya dapat ditingkatkan dengan dibangunnya infrastruktur yang sesuai dengan standar. Pembangunan pasar dari awal pun dapat memberikan kesempatan bagi perusahaan meningkatkan layanan jasa lainnya yang menarik minat pelanggan. Hal tersebut akan menjadi daya tarik tersendiri bagi pelanggan untuk melakukan aktivitas di pasar yang dikelola oleh perusahaan.

\section{Key Partnership}

Hubungan atau sinergi dengan mitra dapat dibangun dengan menetapkan nilai inti dan aturan utama antara perusahaan dengan mitra (Purwaty et al. 2018). Perusahaan perlu melakukan pengawasan secara rutin terhadap kualitas layanan yang diberikan oleh mitra sehingga tidak terjadi penurunan kualitas layanan. Sebagai contohnya, kerjasama antara PDPPJ, dinas kebersihan, pihak pengelolan kebersihan, dengan perusahaan daur ulang dalam penciptaan produk pupuk ataupun produk plastik. Pencitaan produk tersebut tidak hanya mengatasi permasalahan kebersihan yang ada, akan tetapi menciptakan pemasukan baru bagi perusahaan.

\section{Customer Segment}

Pembangunan sumber daya fisik yang lebih baik dan sesuai dengan standar akan menarik tenant-tenant (pelanggan) baru untuk masuk dan menggunakan jasa layanan perusahaan. Kondisi sumber daya fisik yang lebih baik akan menarik pelanggan yang lebih besar dengan penawaran yang jauh lebih baik dibandingkan kondisi saat ini. Hal tersebut nantinya akan berpengaruh 
terhadap peningkatan pendapatan dari biaya sewa perusahaan.

\section{Channels}

Komunikasi secara personal antara perusahaan dengan pelanggan merupakan channel yang paling efektif. Selain itu, perusahaan dapat mengkomunikasikan melalui media sosial untuk membangun kesadaran atas proporsi nilai yang ditawarkan. Keberadaan sosial media juga bisa menjadi wadah bagi pelanggan dalam menyampaikan evaluasi purna jual terhadap perusahaan.

\section{Customer Relationship}

Hubungandenganpelangganperluditingkatkanterutama melalui layanan personal dengan memanfaatkan channels media sosial yang dibangun perusahaan. Hal ini terutama dilakukan untuk mempertahankan dan meningkatkan intensitas komunikasi dengan pelanggan dan calon pelanggan. Layanan otomatis juga dapat dilakukan misal melalui profil online (website) yang memberikan kebebasan pelanggan (calon) untuk mengakses kebutahan informasi yang diinginkan.

\section{Cost Structure}

Elemen cost structure yang perlu diperhatikan adalah biaya perawatan infrastruktur yang diharapkan menggunakan sistem yang jauh lebih baik dan otomatis (modern) setelah dilakukannya kegiatan runtuh bangun. Perusahaan dapat melakukan efisiensi biaya dengan cara bekerjasama dengan mitra untuk melakukan penghematan dalam melaksanakan kegiatan perbaikan infrastruktur. Perusahaan juga perlu mengoptimalisasikan penggunaan sumber daya yang ada, dan memberikan aturan tegas kepada pelanggan sehingga tidak ada lagi biaya-biaya yang tidak diprediksi dikeluarkan.

\begin{tabular}{|c|c|c|c|c|c|}
\hline Key Partner & Key Activities & \multicolumn{2}{|c|}{ Value Proposition } & Customer Relationship & Customer Segment \\
\hline \multirow[t]{3}{*}{$\begin{array}{l}\text { - Investor } \\
\text { - Pihak Ketiga } \\
\text { (Pengelola parkir, } \\
\text { bongkar muat, } \\
\text { kebersihan, MCK) } \\
\text { - Kerjasama secara } \\
\text { lebih spesifik dengan } \\
\text { mitra* }\end{array}$} & $\begin{array}{l}\text { - Pembangunan dan } \\
\text { Pemeliharaan } \\
\text { - Pengelolaan dan } \\
\text { Pengawasan } \\
\text { - Revitalisasi* } \\
\text { - E-Retribusi* } \\
\text { - Pelatihan untuk } \\
\text { peningkatan } \\
\text { kapabilitas sumber } \\
\text { daya* } \\
\end{array}$ & \multirow{3}{*}{\multicolumn{2}{|c|}{$\begin{array}{l}\text { - Accessibility } \\
\text { - Getting the job done } \\
\text { - Cost reduction } \\
\text { - Convenience/usability } \\
\text { - Peningkatan kualitas } \\
\text { layanan dengan sistem } \\
\text { otomatis* } \\
\text { - Penataan PKL* } \\
\text { - Penciptaan produk dan } \\
\text { layanan baru* }\end{array}$}} & $\begin{array}{l}\text { - Kantor pusat dan } \\
\text { kantor unit } \\
\text { - Website dan call } \\
\text { center } \\
\text { - Pemanfaatan database } \\
\text { pelanggan* } \\
\text { - Sosial media } \\
\text { interaktif* }\end{array}$ & \multirow[t]{3}{*}{$\begin{array}{l}\text { - } \text { Pedagang } \\
\text { - Meningkatkan } \\
\text { pedagang terutama } \\
\text { tenant besar* } \\
\text { - Pembeli } \\
\text { - Meningkatkan jumlah } \\
\text { pengunjung* }\end{array}$} \\
\hline & Key Resources & & & Channel & \\
\hline & $\begin{array}{l}\text { - Sumber daya fisik } \\
\text { (bangunan) } \\
\text { - Revitalisasi* } \\
\text { - Sumber daya manusia } \\
\text { - Tenaga ahli khusus* }\end{array}$ & & & $\begin{array}{l}\text { - Saluran langsung } \\
\text { (kantor unit, website, } \\
\text { call center) } \\
\text { - Sosial media } \\
\text { interaktif* } \\
\text { - Website dan petunjuk } \\
\text { layanan* }\end{array}$ & \\
\hline \multicolumn{3}{|l|}{ Cost Structure } & \multicolumn{3}{|c|}{ Revenue Streams } \\
\hline \multicolumn{3}{|c|}{$\begin{array}{l}\text { - Biaya umum } \\
\text { - Perawatan infrastruktur } \\
\text { - Biaya tenaga kerja } \\
\text { - Efisiensi biaya melalui pengoptimalan penggunaan sumber daya } \\
\text { dan kerjasama dengan mitra* }\end{array}$} & \multicolumn{3}{|c|}{$\begin{array}{l}\text { - Biaya sewa } \\
\text { - Investor } \\
\text { - Profit sharing jasa layanan } \\
\text { - Pemasukan dari penyediaan layanan jasa baru* } \\
\text { - Peningkatan pemasukan dari meningkatnya okupansi* }\end{array}$} \\
\hline
\end{tabular}

Gambar 3. Pengembangan (*) model bisnis kanvas PD Pasar Pakuan Jaya 


\section{Revenue Stream}

Perusahaan perlu meningkatkan pemahaman kesediaan pelanggan membayar terhadap proporsi nilai yang ditawarkan. Evaluasi proporsi nilai perlu dilakukan sehingga transaksi berkelanjutan. Perusahaan perlu melakukan otomatisasi dalam rangka meningkatkan kedisiplinan pelanggan dalam melakukan pembayaran, serta meningkatkan kepercayaan antara perusahaan dan pelanggan.

\section{Implikasi Manajerial}

Berdasarkan penelitian yang telah dilakukan untuk menyusun strategi perbaikan dan pengembangan pengelolaan pasar oleh PDPPJ melalui pendekatan business model canvas, elemen yang perlu mendapatkan perhatian lebih adalah elemen key resources dan key activities, yaitu dengan melakukan revitalisasi pasar dan meningkatkan kemampuan sumber daya manusia dalam memberikan pelayanan dan pemasaran. Implikasi manajerial yang bisa diberikan berdasarkan hasil tersebut adalah, (1) pembangunan lokasi pasar dengan arsitektur dan layout yang disesuaikan dengan kebutuhan dan zonasi yang spesifik sehingga aktivitas jual beli dapat dilakukan secara nyaman dan kondusif bagi pengunjungdan pedagang. Pembangunan dan pembenahan pasar hendaknya mengedepankan kepentingan para pedagang dan konsumen bukan kepentingan investor semata (Daryanto, 2009). (2) Peningkatan kualitas layanan dengan sistem otomatisasi, sehingga proposisi nilai dan penggunaan sumber daya efektif dan efisien. Penerapan e-retribusi akan menangani permasalahan pungutan liar, kerugian akibat adanya ketidakdisiplinan pembayaran, dan meningkatkan kepercayaan antara perusahaan dan pelanggan, penerapan otomatisasi pada layanan fasilitas umum seperti perparkiran, bongkar muat, dan pengelolaan listrik akan mengurangi kesemerawutan kondisi di lokasi pasar. Penerapan SOP dan aturan tegas bagi petugas dan mitra akan meningkatkan kualitas layanan yang diberikan. (3) Peningkatan komunikasi dan pemasaran terhadap pelanggan. Perusahaan perlu menetapkan sistem pemasaran yang sesuai untuk menjaga pelanggan lama dan mendapatkan pelanggan baru, komunikasi yang digunakan harus dipastikan memberikan informasi yang jelas dibandingkan hanya sekedar iklan (Polakova et al. 2015). Saat ini perusahaan hanya bergantung pada keberadaan kantor unit, sehingga tidak banyak masyarakat yang mengetahui mengenai layanan yang diberikan oleh perusahaan. Penciptaan website yang informatif, lengkap, dan diperbarui secara berkala akan menarik calon pelanggan baru untuk menggunakan layanan yang ditawarkan. Penggunaan sosial media yang interaktif dengan masyarakat juga akan meningkatkan kesadaran masyarakat akan layanan yang diberikan oleh perusahaan secara lebih baik.

\section{KESIMPULAN DAN SARAN}

\section{Kesimpulan}

Model bisnis PDPPJ berdasarkan BMC menunjukan bahwa customer segmennya adalah pedagang dan pengunjung pasar, proposisi nilai yang ditawarkan meliputi kemudahan untuk mengakses pasar bagi pedagang, pembuatan perizininan untuk berdagang, layanan fasilitas umum, dan layanan pasar tradisional bagi pelanggan. Channels yang dijalankan adalah saluran langsung melalui kantor pusat dan unit, perusahaan menjaga hubungan pelanggan dengan sistem bantuan secara personal kepada pelanggan. Aktivitas yang dilakukan meliputi pembangunan dan pemeliharaan infrastruktur, serta pengelolaan dan pengawasan pasar tradisional. Sumberdaya utama perusahaan adalah sumber daya fisik dan sumber daya manusia. Kemitraan yang dijalin dengan pihak ketiga dalam pengelolaan jasa layanan, dan investor yang membantu dalam pembangunan dan pemeliharaan infrastruktur. Cost structure meliputi biaya gaji, biaya umum, dan biaya pemeliharaan infrastruktur sementara revenue stream dihasilkan dari biaya sewa.

Hasil analisis persepsi pelanggan, pedagang dan pengunjung merasa cukup puas dengan kualitas layanan yang diberikan oleh PDPPJ. Akan tetapi, pedagang dan pembeli mengharapkan adanya peningkatan kualitas layanan dari perusahaan untuk tetap bertahan. Berdasarkan hasil benchmark, fasilitas dan layanan yang diberikan oleh PDPPJ masih tertinggal dibandingkan Pasar Rejowinangun dan Pasar Modern BSD. PDPPJ perlu melakukan peningkatan infrastruktur dan kualitas layanan agar tidak pelanggan tidak berpindah pada pesaing.

Strategi pengembangan dilakukan dengan cara revitalisasi secara total terhadap sumber daya fisik perusahaan. Pengembangan juga dilakukan pada kualitas sumber daya manusia perusahaan. PDPPJ perlu menarik sumber daya manusia yang memiliki kapabilitas tinggi. Penggunaan teknologi dan media 
sosial dalam memperkuat hubungan dengan pelanggan perlu dilakukan, untuk menarik segmen pelanggan baru.

\section{Saran}

Berdasarkan penelitian yang telah dilakukan, perusahaan perlu melakukan penyesuaian sumber daya dan aktifitasnya dengan kebutuhan pelanggan. Dengan demikian kegiatan dan layanan yang diberikan oleh perusahaan akan tepat sasaran bagi pelanggannya. Terdapat beberapa hal yang dapat dikaji lebih mendalam, khususnya mengenai potensi pengembangan pengelolaan melalui kerjasama dengan mitra, dan ancaman bagi perusahaan dalam menghadapi pedagang kaki lima.

\section{DAFTAR PUSTAKA}

Agustiadi A, Syarief R, Nurrochmat DR. 2018. Strategi pengembangan bisnis rental mobil Wiralodra 27 dengan pendekatan model bisnis kanvas. Jurnal Aplikasi Bisnis dan Manajemen 4(1):138-150.

Bakri M . 2011. Strategi peningkatan posisi tawar pasar tradisional terhadap pedagang di Kota Bogor [tesis]. Bogor: Institut Pertanian Bogor.

[BPS] Badan Pusat Statistik. 2018. Kota Bogor dalam Angka 2018. Bogor: BPS Kota Bogor.

Daryanto A. 2009. Revitalisasi Pasar Tradisional http:// ariefdaryanto.blog.mb.ipb.ac.id/files/2010/07/ Revitalisasi-Pasar-Tradisional_Agu09.pdf[2019 Jan 7].

[Disperindag] Dinas Perdagangan dan Perindustrian Kota Bogor. 2016a. Data Kios dan Los di Pasar Tradisional Kota Bogor. Bogor: Disperindag

[Disperindag] Dinas Perdagangan dan Perindustrian Kota Bogor. 2016b. Pendapatan Asli Daerah Kota Bogor. Bogor: Disperindag

Fitzsimmons JA, Fitzsimmons MJ, Bordoloi SK. 2014. Services Management: Operations, Strategy, and Information Technology. New York: McGraw Hill.

Kotler P, Keller KL. 2009. Manajemen Pemasaran Ed ke-13 Jilid ke-1. Jakarta. Erlangga.

Muslimin L, Indriati F, Widayanti T. 2011. Kajian model pengembangan pasar tradisional. Buletin Ilmiah Penelitian dan Pengembangan Perdagangan 1(2): 3-46.
Nurhakim AS. Suparno O. Nurrochmat DR. 2018. Pengembangan model bisnis dan strategi pelayanan kesehatan. Jurnal Aplikasi Bisnis dan Manajemen 4(2):251.

Osterwalder A. 2004. The business model ontology a proposition a design science approach [these]. Zurich: Universite De Lausanne Ecole Des Hautes Estudes Commerciales.

Osterwalder A dan Y. Pigneur. 2012. Business Model Generation. Jakarta: PT Elex Media Komputindo.

Pemerintah Republik Indonesia. 2014. Undang-Undang Nomor 23 Tahun 2014 tentang pemerintah daerah. Jakarta: Sekretariat Negara.

Polakova J, Kolackova G, Ticha I. 2015. Performance implications of business model change : a case study. Acta Universitatis Agriculturae et Silviculturae Mendelianae Brunensis 63(6): 2101-2107.

Prasetio A. 2012. Pengaruh kualitas pelayanan dan harga terhadap kepuasan pelanggan. Management Analysis Journal 1(2):1-8.

Purwaty H, Oktaviani R, Suparno O. 2018. Eel business development strategy in PT Laju Banyu Semesta (LABAS). Indonesian Journal of Business and Entrepreneurship 4(1): 100-109.

Qastharin AR. 2016. Business model canvas for social enterprise. Journal of Business and Economiscs 7(4): 627-637.

Reardon T, Berdegue J, Timmer CP. 2005. Supermarketization of the 'emerging markets' of the pacific rim: development and trade implications. Journal of Food Distribution Research 36(1): 3-12.

Reardon T, Timmer CP, Marten B. 2010. Supermarket revolution in asia and emerging development strategies to include small farmers. Proceedings of the National Academy of Sciences 109(31): 12332-12337.

Sari SP. 2012. Strategi pengembangan pengelolaan pasar di Kota Dumai [tesis]. Bogor: Institut Pertanian Bogor.

Soliha E. 2008. Analisis industri ritel di Indonesia. Jurnal Bisnis dan Ekonomi 15(2): 128-142.

Suryadarma D, Poesoro A, Budiyati S, Akhmadi, Rosfadhila M. 2007. Dampak Supermarket terhadap Pasar dan Pedagang Ritel Tradisional di Daerah Perkotaan di Indonesia. Jakarta: Lembaga Penelitian SMERU. 
Wijaya H, Beik IS, Sartono B. 2017. Pengaruh kualitas layanan terhadap kepuasan dan loyalitas nasabah bank syariah xyz di Jakarta. Jurnal Aplikasi Bisnis dan Manajemen 3(3): 417-426.

Wiska F, SyariefR, Baga LM. 2016. Developing sekolah peternakan rakyat program using the business canvas approach (Case study: Bojonegoro
Regency). Indonesian Journal of Business and Entrepreneurship 2(2): 69-81.

Youssef KB. Giuseppe G. Michela P. 2016. An exploration on the use of canvas business model to create value in a food sector. International Conference on Marketing and Business Development 2(1): 180-193. 